\title{
Frailty screening by Geriatric-8 and 4-meter gait speed test is feasible and predicts postoperative complications in elderly colorectal cancer patients
}

Citation for published version (APA):

Bessems, S. A. M., Konsten, J. L. M., Vogelaar, J. F. J., Csepan-Magyar, R., Maas, H. A. A. M., van de Wouw, Y. A. J., \& Janssen-Heijnen, M. L. G. (2021). Frailty screening by Geriatric-8 and 4-meter gait speed test is feasible and predicts postoperative complications in elderly colorectal cancer patients. Journal of Geriatric Oncology, 12(4), 592-598. https://doi.org/10.1016/j.jgo.2020.10.012

Document status and date:

Published: 01/05/2021

DOI:

10.1016/j.jgo.2020.10.012

Document Version:

Publisher's PDF, also known as Version of record

\section{Document license:}

Taverne

Please check the document version of this publication:

- A submitted manuscript is the version of the article upon submission and before peer-review. There can be important differences between the submitted version and the official published version of record.

People interested in the research are advised to contact the author for the final version of the publication, or visit the DOI to the publisher's website.

- The final author version and the galley proof are versions of the publication after peer review.

- The final published version features the final layout of the paper including the volume, issue and page numbers.

Link to publication

\footnotetext{
General rights rights.

- You may freely distribute the URL identifying the publication in the public portal. please follow below link for the End User Agreement:

www.umlib.nl/taverne-license

Take down policy

If you believe that this document breaches copyright please contact us at:

repository@maastrichtuniversity.nl

providing details and we will investigate your claim.
}

Copyright and moral rights for the publications made accessible in the public portal are retained by the authors and/or other copyright owners and it is a condition of accessing publications that users recognise and abide by the legal requirements associated with these

- Users may download and print one copy of any publication from the public portal for the purpose of private study or research.

- You may not further distribute the material or use it for any profit-making activity or commercial gain

If the publication is distributed under the terms of Article 25fa of the Dutch Copyright Act, indicated by the "Taverne" license above, 


\section{Frailty screening by Geriatric- 8 and 4-meter gait speed test is feasible and predicts postoperative complications in elderly colorectal cancer patients}

\section{Stan A.M. Bessems ${ }^{\text {a,* }}$, Joop L.M. Konsten a , Jeroen F.J. Vogelaar ${ }^{\text {a }}$, Reka Csepán-Magyar ${ }^{\text {b }}$, Huub A.A.M. Maas ${ }^{\text {c }}$, Yes A.J. van de Wouw ${ }^{\mathrm{d}}$, Maryska L.G. Janssen-Heijnen ${ }^{\mathrm{e}, \mathrm{f}}$}

a Department of Surgery, VieCuri Medical Centre, Venlo, the Netherlands

b Department of Geriatric Medicine, VieCuri Medical Centre, Venlo, the Netherlands

c Department of Geriatric Medicine, Elisabeth-TweeSteden Hospital, Tilburg, the Netherlands

${ }^{\mathrm{d}}$ Department of Medical Oncology, VieCuri Medical Centre, Venlo, the Netherlands

e Department of Clinical Epidemiology, VieCuri Medical Centre, Venlo, the Netherlands

${ }^{\mathrm{f}}$ Department of Epidemiology, GROW School for Oncology and Developmental Biology, Maastricht, the Netherlands

\section{A R T I C L E I N F O}

\section{Article history:}

Received 20 March 2020

Received in revised form 29 May 2020

Accepted 19 October 2020

Available online 4 November 2020

\section{Keywords:}

Colorectal cancer

Frailty

Frailty screening

Geriatric-8

Gait speed test

Postoperative complications

\begin{abstract}
A B S T R A C T
Introduction: Identification of frail older colorectal cancer patients might help to select those prone to adverse events and may lead to adjustment of treatment plans. However, the prognostic validity of screening for frailty is unknown.

Methods: This retrospective study evaluates colorectal cancer patients $\geq 70$ years who underwent elective surgery between May 2016 and December 2018. The Geriatric-8 (G8) and 4-m gait speed test (4MGST) were used as frailty screening tools. According to hospital guidelines, patients were referred to a geriatrician when screening was indicative for frailty (G8 $\leq 14$ and/or 4MGST $<1 \mathrm{~m} / \mathrm{s}$ ). Patients were categorized as fit, vulnerable or frail by comprehensive geriatric assessment (CGA). The clinical implications and prognostic validity of frailty screening and CGA were evaluated.

Results: 149 patients were included, of whom 132 (89\%) were screened for frailty. Frailty was suspected in $40 \%$ of screened patients $(n=53)$ of whom $89 \%(n=47)$ was referred for CGA. A higher complication rate was seen in patients with G8 $\leq 14$ and/or 4MGST $<1 \mathrm{~m} / \mathrm{s}$ compared to those with G8 $>14$ and 4MGST $\geq 1 \mathrm{~m} / \mathrm{s}$ (respectively $62 \%$ versus $28 \%, p<0.001)$. Pneumonia ( $21 \%$ versus $6 \%, p=0.013$ ) and cardiac complications ( $11 \%$ versus $4 \%$, $p=0.093$ ) were more prevalent in patients with G8 $\leq 14$ and/or 4MGST $<1 \mathrm{~m} / \mathrm{s}$. CGA identified frail patients as a group with a high complication rate of $68 \%$.

Conclusion: Screening for frailty with subsequent referral for CGA is feasible in older colorectal cancer patients. Our study suggests that screening for frailty by G8 + 4MGST can identify patients with higher risk for postoperative complications.
\end{abstract}

(c) 2020 Elsevier Ltd. All rights reserved.

\section{Introduction}

Older adults represent a substantial part of colorectal cancer patients. In the Netherlands, $54 \%$ of patients with colorectal carcinoma are currently $\geq 70$ years old at diagnosis [1].

Surgery for colorectal cancer in older patients is associated with increased morbidity and mortality. Complication rates range between 20 and $50 \%$ and one-year excess mortality rates are reported up to 16\%. [2] Patient characteristics such as pre-operative health status, comorbidity and frailty are associated with postoperative complications and even death [3-5]. Frailty implies poor homeostatic capacity, even

* Corresponding author at: Department of Surgery, Tegelseweg 210, 5912 BL Venlo, the Netherlands.

E-mail address: sbessems@viecuri.nl (S.A.M. Bessems). in presence of minor stressors, and leads to an increased risk for adverse health outcomes. It is thought to be a consequence of cumulative decline in many physiological systems and comorbidities.

Frailty can be identified by comprehensive geriatric assessment (CGA); CGA includes a multidisciplinary examination and intervention plan for patients with an assessment of their physical, psychological, functional and social status. Pre-operative assessment in all patients by CGA is time-consuming and expensive [6]. Therefore, frailty screening tools have been validated, both to identify patient groups which are at risk for adverse outcomes and to select those patients who may benefit most from performing a more detailed assessment with CGA. In particular the Geriatric-8 (G8) and the 4-m gait speed test (4MGST) seem to be clinically relevant and well validated tools. [7-9]

In the Netherlands, frailty screening and CGA are implemented in colorectal cancer care-pathways nationwide since 2015. However, the 
feasibility and clinical implications of this implementation has been scarcely investigated. Earlier studies concerning CGA in older colorectal cancer patients demonstrate that CGA can predict postoperative complications $[10,11]$. The prognostic validity of abovementioned frailty screening tools with respect to postoperative outcome in this patient category remains unclear. [12,13] Frailty screening or CGA leads to alternations in oncological treatment strategies in frail elderly with various cancer types. [14] Whether surgical or oncological treatment strategies are changed by frailty screening or CGA in older patients with colorectal carcinoma is unclear.

The aim of this study is to examine the feasibility and clinical implications of frailty screening by G8 and 4MGST with subsequent referral for CGA, as well as the prognostic validity of G8 + 4MGST and CGA on postoperative outcome in older colorectal cancer patients.

\section{Material and Methods}

\subsection{Study Design and Population}

\subsubsection{Study Population}

Our study is single centre (VieCuri Medical Centre, a training hospital in The Netherlands) retrospective observational study. This study was approved by the local ethics committee. Due to the retrospective design of the study with anonymized data analysis, an exemption status for individual informed consent was provided.

Patients aged 70 years or older were included once they underwent elective surgery for colorectal cancer between May 2016 and December 2018. Surgery was performed with curative intent. Exclusion criteria were recurrent disease or palliative treatment intention.

\subsubsection{Pre-Operative Frailty Screening and Comprehensive Geriatric Assessment}

All patients aged $\geq 70$ underwent pre-operative screening for frailty using the G8 screening test and the 4MGST. These tests were performed by specialized nurses as part of standard care which takes about 5 min to complete.

The G8 test contains 8 questions on multiple domains (appetite, weight loss, BMI, mobility, polypharmacy, patient-related health, age category), and its scoring system ranges from 0 to 17 . The 4MGST measures the time used for a patient to walk $4 \mathrm{~m}$ at a normal pace. A positive screening result was defined as G8 score $\leq 14$ and/or the 4MGST $<1 \mathrm{~m} / \mathrm{s}$ [7]. According to hospital guidelines, patients with a positive screening should be referred for CGA by a geriatrician.

CGA consisted of assessment of comorbid diseases, activities of daily living (ADL), instrumental activities of daily living (IADL), nutritional status by mini nutritional assessment short form (MNA-SF), cognitive status by mini mental state examination (MMSE), and the evaluation of neuropsychological problems based on a semi-structured mental status interview. Comorbidities were categorized and graded according the CIRS-G classification [15-17]. Within the CIRS-G each disease category is graded on a scale from 0 to 4 : 0 meaning no comorbidity in that category is present and 1-4 meaning comorbidity is present with 4 being a severe/life threatening comorbidity. Activities of daily living were measured using the KATZ-index, a six item questionnaire. The score ranges from 0 to 6,0 being dependent on all six items, 6 being completely independent [18]. The Fillenbaum test, which is a 7 item questionnaire in which the score per item ranges from 0 to 2, 0 being completely dependent and 2 being independent, a total score of 14 represents complete instrumental independency, was used to measure IADL [19]. The MNA-SF scores are categorized as 0-7 (severe) malnutrition, 8-11 at risk for malnutrition, 11-14 no malnutrition [20]. The MMSE is a 30 item questionnaire in which patients are assessed on cognitive impairment, and scores range from 0 to 30. [21]

Classification of patients into fit, vulnerable or frail was done according one of the algorithms described by the International Society of Geriatric Oncology (SIOG). [22,23] The SIOG2 algorithm was chosen and modified as it is a validated prognostic performance measure which uses variables that are in concordance with the measures included in the CGA taken by geriatricians in the VieCuri Medical Centre. The modified algorithm is presented in Table 1.

The CGA deviates from the algorithm described by SIOG2 on one variable. While SIOG2 uses Lawton \& Brody test to evaluate IADL scores, in this study only the Fillenbaum test was available. [19,24] For the Fillenbaum test a cut-off value of $>12$ was chosen, which is in resemblance with being dependent on 1 item in the Lawton and Brody test.

\subsubsection{Data Collection and Outcome Measures}

Data was collected from the electronic patient records using Castor Electronic Data Capture [online] Available at: https://castoredc.com. Patient characteristics were collected including: gender, age, BMI, comorbidities, pre-operative hemoglobin levels, G8 score, 4MGST, CGA outcome. Tumour characteristics were collected including: p-TNM, the number of (positive) lymph nodes, lymphovascular invasion and differentiation grade. Treatment characteristics were collected including: surgical treatment strategy (type of resection, primary anastomosis, protective stoma, laparoscopy), oncologic treatment (type of chemotherapy and radiotherapy), and treatment alterations as advised by the geriatrician. Furthermore, data on length of hospital stay, complications, date of last follow-up and 30-day mortality were collected.

The primary outcome measure was the occurrence of postoperative complications $<30$ days. Postoperative complications included: surgical (anastomotic leakage, abscess, wound infection, ileus), pulmonary, cardiologic, genital-urinary tract, thrombo-embolic complications, delirium and electrolyte disorders. The severity of complications was assessed by the Clavien-Dindo classification [25,26]. Re-interventions (surgical or radiologic) and re-admission within 30 days were also recorded. Postoperative mortality was defined as death within 30 days. Secondary outcome measures were the frequency of (non-)oncologic treatment alterations, like referral to other medical specialist, referral to paramedics (physiotherapist, psychologist and dietician), changes in medication or delirium prevention as advised by the geriatrician.

\subsubsection{Statistical Analyses}

Statistical analyses were performed using IBM SPSS Statistics v.24 (Armonk, NY: IBM Corp. 2016). Categorical variables were displayed by frequencies and percentages, continuous variables by means and standard deviation (SD). Patient, tumour and treatment characteristics, treatment outcomes and treatment alterations were compared between frailty groups using chi-square test, unpaired t-test, Mann-Whitney $U$ test, ANOVA or Kruskal-Wallis dependent on the number of groups and distribution of variables.

\section{Results}

A total of 163 patients aged 70 or older at diagnosis, undergoing surgery for colorectal carcinoma, were eligible for inclusion. (Fig. 1) The mean age of included patients was 78 years (range $70-90$ ) and $58 \%$ of patients were male. Fourteen patients were excluded ( 11 because of recurrent disease and 3 because of a palliative treatment intention), 149 patients met the inclusion criteria.

At last, patients ( $n=17$ ) without frailty screening were not included for further analysis as demonstrated in Fig. 1. However, 13 of these patients were directly referred for CGA based on the clinical judgement of the treating physician. Eventually 10 patients were categorized as frail.

\subsection{Geriatric Screening and Geriatric Assessment: Scores and Referral Rates} (Fig. 1)

A flow chart on referral rates for CGA and frailty prevalence is demonstrated in Fig. 1. The proportion of patients screened for frailty, in which at least the G8 was available, was $89 \%(n=132)$. Four-meter gait speed test scores were available in $78 \%(n=116)$. 
Table 1

Algorithm of frailty classification.

\begin{tabular}{ccc}
\hline Frailty classification according SIOG2 $(22, \mathbf{2 3})$ & \\
\hline Fit $=$ & Vulnerable $=$ & Frail $=$ \\
G8 $>14$ and & G8 $\leq 14$ and $/$ or & G $8 \leq 14$ and $/$ or \\
$4 \mathrm{MGST} \geq 1 \mathrm{~m} / \mathrm{s}$ & $4 \mathrm{MGST}<1 \mathrm{~m} / \mathrm{s}$ & $4 \mathrm{MGST}<1 \mathrm{~m} / \mathrm{s}$
\end{tabular}

AND

No grade 4 comorbidity

AND

IADL score $>12 / 14 *$

AND

MMSE score $>24 / 30$

AND

1 grade 3 comorbidity

OR

$\geq 1$ grade 2 comorbidity

OR

At risk for malnutrition

OR

$\mathrm{ADL}>3 / 6$
AND

$\geq 1$ grade 4 comorbidity

OR

$\geq 2$ grade 3 comorbidity

OR

IADL score $\leq 12 / 14$

OR

MMSE score $<24 / 30$

OR

Severe malnutrition

OR

$\mathrm{ADL} \leq 3 / 6$

OR

Depression

Fifty-three patients had positive frailty screening results (G8 $\leq 14$ and/or $4 \mathrm{MGST}<1 \mathrm{~m} / \mathrm{s}$ ) of whom 47 (89\%) were referred for CGA. Seventy-nine patients had negative frailty screening results (G8 $>14$ and $4 \mathrm{MGST} \geq 1 \mathrm{~m} / \mathrm{s}$ ) of whom seven were referred for CGA despite of negative screening.

According to the SIOG 2 Frailty algorithm, 55\% ( $n=72), 13 \%$ ( $n=$ $17)$ and $28 \%(n=37)$ of screened patients were categorized respectively as fit, vulnerable and frail. Six (4\%) patients could not be categorized accordingly as they screened positive but were not referred for CGA. The reasons for not performing CGA on these six patients varied, one patient denied referral, two were considered fit by the treating physician even though they screened positive and for the others the reasons were not evident. All six patients underwent surgery.

\subsection{Patient Demographics}

Patient, tumour and treatment characteristics stratified by frailty screening results are shown in Table 2. Patients with scores indicating frailty were older, had a higher ASA-classification, were more often female, had more grade 3-4 comorbidity, more often had a right-sided tumour and were anaemic more often. Scores on the various domains of CGA of patients who were referred to a geriatrician $(n=54)$ are shown in Table 3.

\subsection{Treatment Alterations and Clinical Implications}

Few alterations in treatment plans or pre-operative optimization strategies based on CGA results were seen. Table 4 demonstrates the frequency of advices for treatment alterations or the provision of specific advice regarding pre-operative optimization and postoperative risk minimization (e.g. delirium prevention). Surgical or oncologic treatment was not discouraged in any of the cases. Delirium prevention was ordered most frequently in frail patients $(N=19)$.

\subsection{Prognostic Validity of Frailty Screening and CGA (Table 5)}

Postoperative complications were significantly higher in patients with G8 $\leq 14$ and/or 4MGST $<1 \mathrm{~m} / \mathrm{s}$ compared to patients with G8 $>14$ and 4 MGST $\geq 1 \mathrm{~m} / \mathrm{s}$ ( $62 \%$ versus $28 \%, p<0.001$ ). Especially pneumonia appeared more frequent in patients with screening results indicative of frailty, $21 \%$ versus $6 \%$ of patients with negative frailty screening $(p=0.013)$. A trend towards more cardiac complications was seen, $11 \%$ in the group with G8 $\leq 14$ and/or 4 MGST $<1 \mathrm{~m} / \mathrm{s}$ versus $4 \%$ in the group of patients without screening results indicative for frailty $(p=0.093)$. Notably, patients who screened positive on G8 + 4MGST were significantly more often in need of postoperative blood transfusion due to blood loss during operation and/or preoperative anaemia ( $25 \%$ versus $10 \%, p=0.027$ ) and their mean length of hospital stay was one day longer ( 9 versus 8 days, $p=0.009$ ).

Significant differences in postoperative outcomes were likewise present when patients were categorized by CGA, according to the modified SIOG2 algorithm. Patients categorized as frail had significantly more complications compared to fit or vulnerable patients, respectively $68 \%$ versus $28 \%$ and $35 \%(p<0.001)$. Pneumonia was seen significantly more often in frail patients compared to fit and vulnerable patients, respectively $22 \%$ versus $12 \%$ and $6 \%(p=0.041)$. The mean length of hospital stay was significantly different for the three groups respectively 8 , 6 and 9 days in fit, vulnerable and frail patients $(p=0.001)$.

No significant differences in re-intervention, readmission or shortterm mortality were noticed between groups.

\section{Discussion}

This retrospective observational study in 149 older colorectal cancer patients undergoing elective surgery demonstrates that screening for frailty by G8 and 4MGST with subsequent referral for CGA is feasible, as $89 \%$ of included patients were screened and $89 \%$ of identified patients 


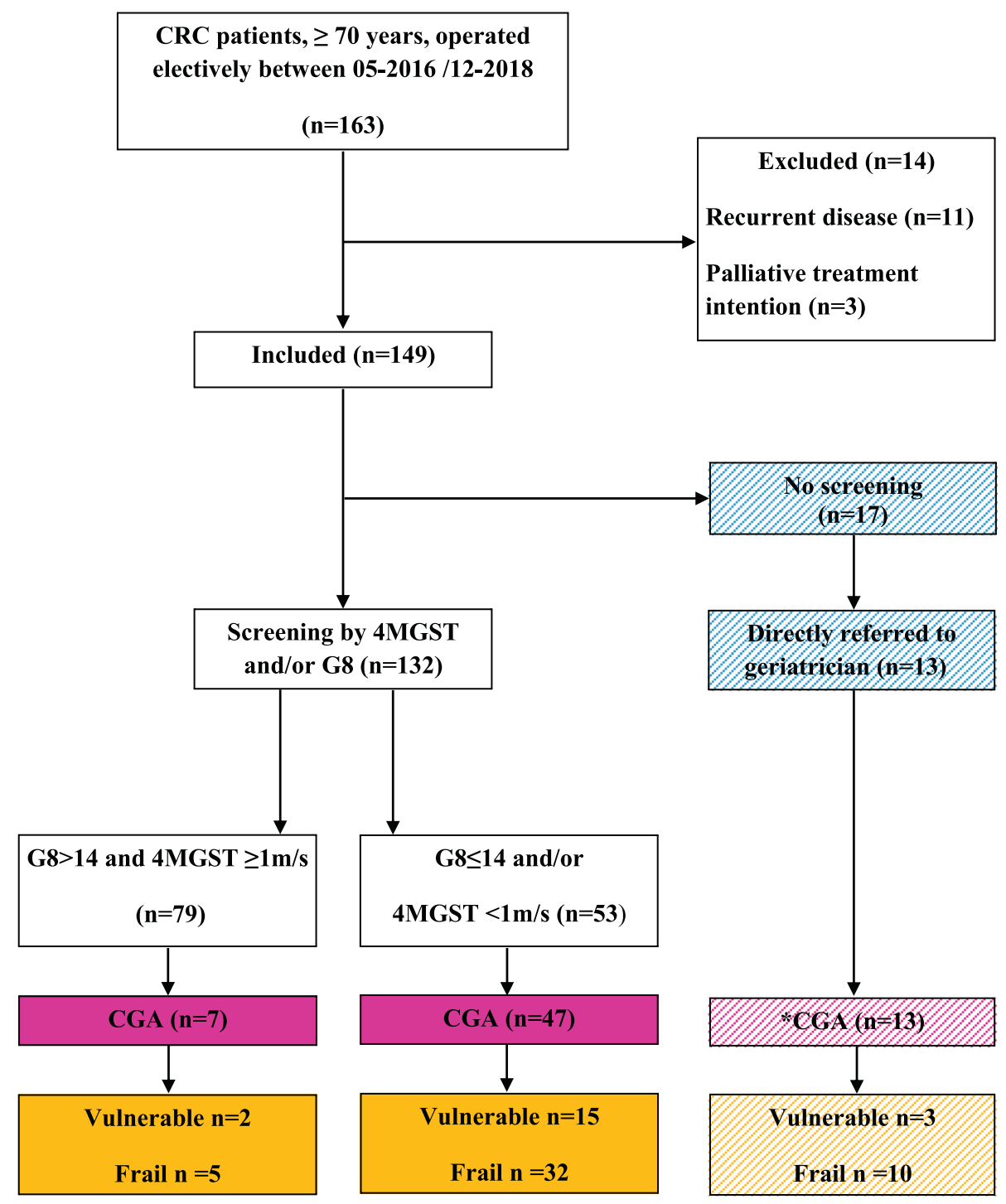

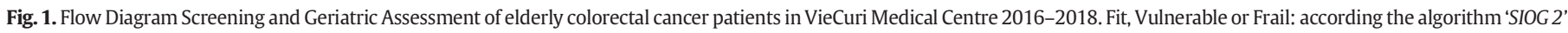
$[22,23] *$ Not screened or assessed according protocol. CRC $=$ colorectal cancer, 4 MGST $=4 \mathrm{~m}$ gait speed tests, CGA $=$ Comprehensive Geriatric Assessment.

were adequately referred for CGA. The implementation of two frailty screening tools combined, including a multi-domain questionnaire (G8) and a short physical performance test (4MGST), is clinically relevant as it selects patients with increased risk (62\% versus $28 \%$ ) of postoperative complications. Especially pneumonia (21\% versus $6 \%$ ) and cardiac complications ( $11 \%$ versus $4 \%$ ) were more prevalent in this group. Comprehensive geriatric assessment following frailty screening can select a considerable subgroup of frail patients, with a prevalence of $28 \%$, who have a remarkably high postoperative complication rate (68\%). Our study demonstrates that geriatricians are reluctant in advising against surgery or oncological treatment in frail colorectal cancer patients. Advice on non-oncologic treatment alterations, such as delirium prevention, was more prevalent and was ordered in 51\% of frail patients.

The frailty prevalence of $28 \%$ in our study is substantially lower compared to the $42 \%$ reported by a recent meta-analysis, in which patients with both solid and hematologic cancers were analysed [3]. Studies including solely colorectal cancer patients demonstrated an even higher prevalence of 43-63.7\% [4,27]. It may be hypothesized that in the current study a small number of frail patients were missed as they were not referred for CGA because of their negative frailty screening results.
This hypothesis is substantiated by the fact that 5 out of 7 patients, referred for CGA despite of negative frailty screening results, appeared to be frail. Moreover, the sensitivity of G8 is estimated to be $90.1 \%$, when frailty is defined as impairment in at least one domain of CGA [28]. The wide range in frailty prevalence might also be the result of different cut-offs for frailty between the two studies mentioned above and the current one. $[4,27]$ Another possible explanation for the lower frailty prevalence in our study might be the fact that only operated patients were included in our study. Patients who did not undergo surgery were probably those who were frail. [29]

The current study shows that frailty screening identifies a large proportion of patients with anaemia and consequently patients who require blood transfusions postoperatively. Anaemia in colorectal cancer patients is common; prevalence is estimated at $30 \%$. Iron deficiency is seen in approximately 70\% of colorectal cancer patients with preoperatively discovered anaemia [30]. According to recent literature, implementation of an 'iron deficiency anaemia correction pathway' might result in less blood transfusions and shorter length of hospital stay in patients with corrected anaemia. [30] This indicates that preoperative iron deficiency assessment and correction should be considered in patients with screening results indicative of frailty. 
Table 2

Patient, tumour and treatment demographics stratified by frailty screening.

\begin{tabular}{|c|c|c|c|}
\hline Demographics & $\begin{array}{l}\mathrm{G} 8>14 \text { and } \\
4 \mathrm{MGST} \geq 1 \mathrm{~m} / \mathrm{s} \\
(n=79)\end{array}$ & $\begin{array}{l}\mathrm{G} 8 \leq 14 \text { and } / \text { or } \\
4 \mathrm{MGST}<1 \mathrm{~m} / \mathrm{s} \\
(n=53)\end{array}$ & P-value \\
\hline Age mean $(S D)$ & $76(3.6)$ & $79(5.3)$ & $<0.001$ \\
\hline ASA classification N (\%) & & & 0.045 \\
\hline $1-2$ & $58(73)$ & $30(57)$ & \\
\hline $3-4$ & $21(27)$ & $23(43)$ & \\
\hline Gender N (\%) & & & 0.016 \\
\hline Male & $51(65)$ & $23(43)$ & \\
\hline Female & $28(35)$ & $30(57)$ & \\
\hline BMI mean (SD) & $27(3.7)$ & $26(4.0)$ & 0.169 \\
\hline \multicolumn{4}{|l|}{ G8 } \\
\hline$>14$ & 79 & 3 & \\
\hline$\leq 14$ & - & 50 & \\
\hline \multicolumn{4}{|l|}{ 4MGST N } \\
\hline$\geq 1 \mathrm{~m} / \mathrm{s}$ (fast) & 69 & 27 & \\
\hline$<1 \mathrm{~m} / \mathrm{s}($ slow $)$ & - & 20 & \\
\hline Missing & 10 & 6 & \\
\hline Comorbidity* (CIRS-G) N (\%) & & & 0.007 \\
\hline No & $12(15)$ & $0(0)$ & \\
\hline Grade 1-2 & $52(66)$ & $37(70)$ & \\
\hline Grade 3-4 & $15(19)$ & $16(30)$ & \\
\hline Tumour location N (\%) & & & 0.001 \\
\hline Right sided & $25(32)$ & $33(62)$ & \\
\hline Left sided ${ }^{1}$ & $54(68)$ & $20(38)$ & \\
\hline $\begin{array}{l}\text { Pre-operative Hb level mean } \\
\text { (SD) }\end{array}$ & $8.3(1.0)$ & $7.3(1.0)$ & $<0.001$ \\
\hline Anaemia^ N (\%) & $27(34)$ & $35(66)$ & $<0.001$ \\
\hline Lymph nodes mean (SD) & $14(6.6)$ & $16(8.5)$ & 0.107 \\
\hline Positive lymph nodes mean (SD) & $1(1.3)$ & $1(2.4)$ & 0.790 \\
\hline Differentiation grade $\mathrm{N}(\%)$ & & & 0.119 \\
\hline Well/Moderate & $75(95)$ & $48(91)$ & \\
\hline Poor & $2(2.5)$ & $5(9)$ & \\
\hline Unknown & $2(2.5)$ & $0(0)$ & \\
\hline Lymphovascular invasion N(\%) & $12(15)$ & $5(9)$ & 0.333 \\
\hline Tumour stage $\mathrm{N}(\%)$ & & & 0.459 \\
\hline I & $32(41)$ & $15(28)$ & \\
\hline II & $20(25)$ & $17(32)$ & \\
\hline III & $23(29)$ & $20(38)$ & \\
\hline IV & $2(3)$ & $1(2)$ & \\
\hline Full Laparoscopy ${ }^{2} \mathrm{~N}(\%)$ & $58(73)$ & $41(77)$ & 0.608 \\
\hline Adjuvant therapy N(\%) & $13(16)$ & $7(13)$ & 0.610 \\
\hline Neo adjuvant therapy N (\%) & $10(12)$ & $5(9)$ & 0.567 \\
\hline
\end{tabular}

ASA = American Society of Anesthesiologist physical status classification system, *patients according CIRS-G classification 1 = including rectum, 2 = laparoscopy without conversion ^ for men hemoglobin $<8.5 \mathrm{mmol} / \mathrm{l}$, for women $<7.5 \mathrm{mmol} / \mathrm{l}$.

Prediction of adverse advents by frailty screening tools in older colorectal cancer patients has been studied scarcely. It is unclear which screening tool is most predictive. A recent study demonstrated ISAR$\mathrm{HP}$ is a relevant tool as it predicted a higher risk of postoperative complications. [12] The results of the same study conclude that G8 does not predict increased risk of postoperative complications. The low specificity of G8 in selecting frail patients was suggested as a possible explanation for the lack of predictive value on complications [12]. However, our study demonstrates significant predictive ability of G8 when it is combined with a short physical performance parameter such as the 4MGST.

Identifying patients with increased risk for postoperative complications is essential not only for pre-operative counselling but also for creating targeted approaches to reduce morbidity after colorectal surgery. Recently, strategies such as 'ehanced recovery after surgery'-protocols [31] and shared-care plans after hospital discharge for older patients have been implemented with success [32]. Pre-operative optimization, by multimodal prehabilitation, has been studied recently. Especially physical fitness, malnutrition, iron deficiency anaemia, smoking cessation and psychological resilience are parameters modifiable by prehabilitation. [33,34] However, prehabilitation studies in older colorectal cancer patients in particular show no significant reduction of
Table 3

Outcomes of CGA in 54 patients referred to a geriatrician after frailty screening.

\begin{tabular}{|c|c|}
\hline Variables & $\mathrm{N}=$ \\
\hline \multicolumn{2}{|l|}{$\mathrm{ADL}$} \\
\hline $\mathrm{KATZ}>3$ & 51 \\
\hline $\mathrm{KATZ} \leq 3$ & 1 \\
\hline Miss. & 2 \\
\hline \multicolumn{2}{|l|}{ IADL } \\
\hline Fillenbaum $>12$ & 20 \\
\hline Fillenbaum $\leq 12$ & 32 \\
\hline Miss. & 2 \\
\hline \multicolumn{2}{|l|}{ CIRS G gr 2} \\
\hline None & 10 \\
\hline$\geq 1$ & 44 \\
\hline \multicolumn{2}{|l|}{ CIRS G gr 3} \\
\hline 0 & 44 \\
\hline 1 & 10 \\
\hline$\geq 2$ & 0 \\
\hline \multicolumn{2}{|l|}{ CIRS G gr 4} \\
\hline None & 49 \\
\hline$\geq 1$ & 5 \\
\hline \multicolumn{2}{|c|}{ Malnutrition (MNA) } \\
\hline Absence & 35 \\
\hline At risk & 17 \\
\hline Severe & 2 \\
\hline \multicolumn{2}{|c|}{ Neuropsychological problems } \\
\hline Yes & 7 \\
\hline \multicolumn{2}{|c|}{ Cognitive impairment } \\
\hline MMSE $\geq 24$ & 47 \\
\hline MMSE $<24$ & 7 \\
\hline Total group & 54 \\
\hline
\end{tabular}

Table 4

Advice on (non-)oncologic treatment alterations by a geriatrician after CGA.

\begin{tabular}{lllll}
\hline Treatment modality & \multicolumn{2}{l}{ Vulnerable } & & Frail \\
\cline { 2 - 2 } & $\frac{\mathrm{N}(\%)}{\mathrm{N}(\mathrm{N}=17)}$ & & $\frac{\mathrm{N} \text {-value }}{(\mathrm{n}=37)}$ & \\
\hline Surgical treatment & $0(0)$ & & $0(0)$ & - \\
Oncologic treatment & $0(0)$ & $0(0)$ & - \\
Referral other MS & $1(6)$ & $3(8)$ & 0.627 \\
Referral PM & $2(12)$ & $1(3)$ & 0.230 \\
Medication & $2(12)$ & $2(5)$ & 0.373 \\
Delirium prevention & $4(24)$ & $19(51)$ & $\mathbf{0 . 0 5 0}$ \\
\hline
\end{tabular}

MS: medical specialist, PM: paramedics n.s.: not significant.

complication rates. [33,35-37] A better selection of patients combined with a targeted and personalized approach may be relevant. [33,35-37] Frailty screening using G8 and 4MGST may provide proper selection tools as these tests identify those with increased risk of postoperative morbidity. Referral for CGA could be of added value by outlining a more extensive profile of patients' modifiable risk factors in order to create personalized or targeted prehabilitation programs. Furthermore, in order to be engaged in shared decision-making, patients should be fully informed about risks and benefits of the surgical procedure. In our opinion this should include individualized risk factors like their frailty status.

This study demonstrates that CGA, after preselection by frailty screening with G8 and 4MGST, selects a group of patients with the highest complication risk. Our results, however, also illustrate that geriatricians and treating physicians currently do not rely fully or react on this data as pre-operative optimization methods or changes in treatment plans in frail and fit patients were infrequent. Perhaps associations between frailty and mortality, postoperative dependency, or patients' preferences on postoperative course [38] should be even more evident to justify major treatment alterations as refraining from end-to-end 
Table 5

Post-operative outcome stratified by frailty screening and Modified SIOG 2 Frailty Classification.

\begin{tabular}{|c|c|c|c|c|c|c|c|}
\hline \multirow[t]{4}{*}{ Outcome parameters } & \multicolumn{2}{|l|}{ Frailty screening } & \multirow{3}{*}{ P-value } & \multicolumn{3}{|c|}{ Modified SIOG 2 frailty classification } & \multirow{4}{*}{ P-value } \\
\hline & $\mathrm{G} 8>14$ and $4 \mathrm{MGST} \geq 1 \mathrm{~m} / \mathrm{s}$ & G8 $\leq 14$ and/or 4 MGST $<1 \mathrm{~m} / \mathrm{s}$ & & \multirow{3}{*}{$\frac{\text { Fit }}{\frac{N(\%)}{(n=72)}}$} & \multirow{3}{*}{$\begin{array}{l}\frac{\text { Vulnerable }}{\mathrm{N}(\%)} \\
\mathbf{n}=\mathbf{1 7})\end{array}$} & \multirow{3}{*}{$\frac{\frac{\text { Frail }}{\mathrm{N}(\%)}}{(\mathbf{n}=\mathbf{3 7})}$} & \\
\hline & \multirow{2}{*}{$\begin{array}{l}\mathrm{N}(\%) \\
(\mathbf{n}=\mathbf{7 9}) \\
\end{array}$} & \multirow{2}{*}{$\begin{array}{l}\mathrm{N}(\%) \\
(\mathbf{n}=53)\end{array}$} & & & & & \\
\hline & & & & & & & \\
\hline Post-operative complicated course & $22(28)$ & $33(62)$ & $<0.001$ & $20(28)$ & $6(35)$ & $25(68)$ & $<0.001$ \\
\hline Highest Clavien-Dindo Classification & & & 0.038 & & & & 0.007 \\
\hline I-II & $11(14)$ & $24(45)$ & & $9(13)$ & $5(29)$ & $19(51)$ & \\
\hline III-IV & $11(14)$ & $7(13)$ & & $11(15)$ & $0(0)$ & $5(14)$ & \\
\hline V (30-day mortality) & $0(0)$ & $2(4)$ & & $0(0)$ & $1(6)$ & $1(3)$ & \\
\hline Complication type & & & & & & & \\
\hline Anastomotic leakage & $4(5)$ & $2(4)$ & 0.727 & $4(6)$ & $0(0)$ & $1(3)$ & 0.513 \\
\hline Intra-abdominal abscess & $5(6)$ & $4(8)$ & 0.785 & $5(7)$ & $1(6)$ & $2(5)$ & 0.949 \\
\hline Ileus & $7(9)$ & $8(15)$ & 0.269 & $7(10)$ & $1(6)$ & $6(16)$ & 0.452 \\
\hline Pneumonia & $5(6)$ & $11(21)$ & 0.013 & $4(6)$ & $2(12)$ & $8(22)$ & 0.041 \\
\hline Cardiac complication & $3(4)$ & $6(11)$ & 0.093 & $3(4)$ & $0(0)$ & $4(11)$ & 0.201 \\
\hline Delirium & $2(3)$ & $3(6)$ & 0.356 & $2(3)$ & $0(0)$ & $3(8)$ & 0.268 \\
\hline Blood transfusion & $8(10)$ & $13(25)$ & 0.027 & $8(11)$ & $2(12)$ & $9(24)$ & 0.174 \\
\hline Re-operation because of surgical complication & $5(6)$ & $6(11)$ & 0.680 & $5(7)$ & $0(0)$ & $4(11)$ & 0.354 \\
\hline Mean length of hospital stay in days (SD) & $8(14)$ & $9(9)$ & 0.009 & $8(15)$ & $6(3)$ & $9(10)$ & 0.001 \\
\hline Readmission & $5(6)$ & $4(8)$ & 0.298 & $5(7)$ & $0(0)$ & $3(8)$ & 0.261 \\
\hline
\end{tabular}

Bold signifies p values $<0.05$.

anastomosis, to perform palliative surgery only (decompressing stoma or wig-resections) or to refrain from any surgery. This is substantiated by the fact that occurrences of surgical complications like anastomotic leakage or intra-abdominal abscesses were not different between frail and fit patients as were the occurrences of severe (class III-IV) complications often evoked by surgical complications. The fact that especially pulmonary complications were more prevalent in frail patients emphasizes the potential of prehabilitation in this subgroup of patients. Furthermore, in older and functional dependent patients, colorectal surgery embedded in geriatric-oncological care pathway also had a positive impact on quality of life [39].

The high screening rates in everyday clinical practice and adequacy of referral for CGA according to hospital guidelines strengthen the results of our study. However there are also some limitations to the study possibly affecting its external validity. Since only operated patients were included and CGA was only performed in patients after positive frailty screening, the presented frailty prevalence might be an underestimation. This limited number of patients who were referred for CGA may have impaired statistical power especially in the analysis of subgroups based on CGA, in which the number of events was small for some outcome parameters.

\section{Conclusion}

Screening for frailty by G8 and 4MGST with subsequent referral for CGA is feasible in older colorectal cancer patients. Our study suggests that screening for frailty by G8 + 4MGST can identify patients who are at higher risk for post-operative complications. Future research is necessary to determine whether these patients can benefit from additional interventions (i.e. prehabilitation) or adaptions in care-plans.

\section{Funding}

This study was financed by the Research fund VieCuri Medical Centre. The funding source had no involvement in the study design, the collection, analysis and interpretation of data; in writing of the manuscript; and in the decision to submit the manuscript for publication.

\section{Author contributions}

Study concepts: S.A.M. Bessems, J.L.M. Konsten, M.L.G. Janssen-Heijnen. Study design: S.A.M. Bessems, J.L.M. Konsten, F.J. Vogelaar, R. CsepánMagyar, H.A.A.M. Maas A.J. van de Wouw, M.L.G. Janssen-Heijnen.
Data acquisition: S.A.M. Bessems, J.L.M. Konsten, F.J. Vogelaar, R. Csepán-Magyar, H.A.A.M. Maas A.J. van de Wouw, M.L.G. JanssenHeijnen.

Quality control of data and algorithms: S.A.M. Bessems, J.L.M. Konsten, M.L.G. Janssen-Heijnen.

Data analysis and interpretation: S.A.M. Bessems, J.L.M. Konsten, F.J. Vogelaar, R. Csepán-Magyar, H.A.A.M. Maas A.J. van de Wouw, M.L.G. Janssen-Heijnen.

Statistical analysis: S.A.M. Bessems, J.L.M. Konsten, M.L.G. JanssenHeijnen.

Manuscript preparation: S.A.M. Bessems, J.L.M. Konsten, M.L.G. JanssenHeijnen, F.J. Vogelaar.

Manuscript editing: S.A.M. Bessems, J.L.M. Konsten, F.J. Vogelaar, R. Csepán-Magyar, H.A.A.M. Maas A.J. van de Wouw, M.L.G. JanssenHeijnen.

Manuscript review: S.A.M. Bessems, J.L.M. Konsten, F.J. Vogelaar, R. Csepán-Magyar, H.A.A.M. Maas A.J. van de Wouw, M.L.G. JanssenHeijnen.

\section{Declaration of Competing Interest}

The authors declared no conflicts of interest related to this study.

\section{References}

[1] Dutch ColoRectal Audit. Tien jaar inzicht in Nederlandse darmkanker zorg; 2018 Available from https://dica.nl/jaarrapportage-2018/dcra.

[2] Dekker JW, van den Broek CB, Bastiaannet E, van de Geest LG, Tollenaar RA, Liefers GJ. Importance of the first postoperative year in the prognosis of elderly colorectal cancer patients. Ann Surg Oncol 2011;18(6):1533-9.

[3] Handforth C, Clegg A, Young C, Simpkins S, Seymour MT, Selby PJ, et al. The prevalence and outcomes of frailty in older cancer patients: a systematic review. Ann Oncol 2015;26(6):1091-101.

[4] Ommundsen N, Wyller TB, Nesbakken A, Jordhoy MS, Bakka A, Skovlund E, et al. Frailty is an independent predictor of survival in older patients with colorectal cancer. Oncologist 2014;19(12):1268-75.

[5] Vermillion SA, Hsu FC, Dorrell RD, Shen P, Clark CJ. Modified frailty index predicts postoperative outcomes in older gastrointestinal cancer patients. J Surg Oncol 2017;115(8):997-1003.

[6] Decoster L, Van Puyvelde K, Mohile S, Wedding U, Basso U, Colloca G, et al. Screening tools for multidimensional health problems warranting a geriatric assessment in older cancer patients: an update on SIOG recommendationsdagger. Annals of oncology : official journal of the European society for. Med Oncol 2015;26(2): 288-300.

[7] Pamoukdjian F, Paillaud E, Zelek L, Laurent M, Levy V, Landre T, et al. Measurement of gait speed in older adults to identify complications associated with frailty: a systematic review. J Geriatric Oncol 2015;6(6):484-96. 
[8] Kim HJ, Park I, Lee HJ, Lee O. The reliability and validity of gait speed with different walking pace and distances against general health, physical function, and chronic disease in aged adults. J Exerc Nutr Biochem 2016;20(3):46-50.

[9] Wildiers H, Heeren P. Puts M, Topinkova E, Janssen-Heijnen ML, Extermann M, et al. International Society of Geriatric Oncology consensus on geriatric assessment in older patients with cancer. J Clin Oncol 2014;32(24):2595-603.

[10] Lee YH, Oh H-K, Kim D-W, Ihn MH, Kim JH, Son IT, et al. Use of a comprehensive geriatric assessment to predict short-term postoperative outcome in elderly patients with colorectal Cancer. Ann Coloproctol 2016;32(5):161-9.

[11] Vacante M, Cristaldi E, Basile F, Borzi AM, Biondi A. Surgical approach and geriatric evaluation for elderly patients with colorectal cancer. Updates Surg 2019;71(3): 411-7.

[12] Souwer ETD, Verweij NM, van den Bos F, Bastiaannet E, Slangen RME, Steup WH, et al. Risk stratification for surgical outcomes in older colorectal cancer patients using ISAR-HP and G8 screening tools. J Geriatric Oncol 2018;9(2):110-4.

[13] Fagard K, Casaer J, Wolthuis A, Flamaing J, Milisen K, Lobelle JP, et al. Value of geriatric screening and assessment in predicting postoperative complications in patients older than 70 years undergoing surgery for colorectal cancer. J Geriatric Oncol 2017; 8(5):320-7.

[14] Hamaker ME, Te Molder M, Thielen N, van Munster BC, Schiphorst AH, van Huis LH. The effect of a geriatric evaluation on treatment decisions and outcome for older cancer patients - a systematic review. J Geriatric Oncol 2018;9(5):430-40.

[15] Miller MD, Paradis CF, Houck PR, Mazumdar S, Stack JA, Rifai AH, et al. Rating chronic medical illness burden in geropsychiatric practice and research: application of the cumulative illness rating scale. Psychiatry Res 1992;41(3):237-48.

[16] Kirkhus L, Jordhoy M, Saltyte Benth J, Rostoft S, Selbaek G, Jensen Hjermstad M, et al. Comparing comorbidity scales: attending physician score versus the cumulative illness rating scale for geriatrics. J Geriatric Oncol 2016;7(2):90-8.

[17] Parmelee PA, Thuras PD, Katz IR, Lawton MP. Validation of the cumulative illness rating scale in a geriatric residential population. J Am Geriatr Soc 1995;43(2):130-7.

[18] Katz S, Downs TD, Cash HR, Grotz RC. Progress in development of the index of ADL. Gerontologist 1970;10(1):20-30.

[19] Fillenbaum GG. Screening the elderly. A brief instrumental activities of daily living measure. J Am Geriatr Soc 1985;33(10):698-706.

[20] Soysal P, Isik AT, Arik F, Kalan U, Eyvaz A, Veronese N. Validity of the mini-nutritional assessment scale for evaluating frailty status in older adults. J Am Med Dir Assoc 2019;20(2):183-7.

[21] Folstein MF, Folstein SE, McHugh PR. "Mini-mental state". A practical method for grading the cognitive state of patients for the clinician. J Psychiatr Res 1975;12(3): 189-98.

[22] Droz JP, Aapro M, Balducci L, Boyle H, Van den Broeck T, Cathcart P, et al. Management of prostate cancer in older patients: updated recommendations of a working group of the International Society of Geriatric Oncology. Lancet Oncol 2014;15(9): e404-14.

[23] Ferrat E, Paillaud E, Caillet P, Laurent M, Tournigand C, Lagrange JL, et al. Performance of four frailty classifications in older patients with Cancer: prospective elderly Cancer patients cohort study. J Clin Oncol 2017;35(7):766-77.

[24] Lawton MP, Brody EM. Assessment of older people: self-maintaining and instrumental activities of daily living. Gerontologist 1969;9(3):179-86.
[25] Dindo D, Demartines N, Clavien PA. Classification of surgical complications: a new proposal with evaluation in a cohort of 6336 patients and results of a survey. Ann Surg 2004;240(2):205-13.

[26] Clavien PA, Barkun J, de Oliveira ML, Vauthey JN, Dindo D, Schulick RD, et al. The Clavien-Dindo classification of surgical complications: five-year experience. Ann Surg 2009;250(2):187-96.

[27] Giannotti C, Sambuceti S, Signori A, Ballestrero A, Murialdo R, Romairone E, et al. Frailty assessment in elective gastrointestinal oncogeriatric surgery: predictors of one-year mortality and functional status. J Geriatric Oncol 2019;10(5):716-23.

[28] Pamoukdjian F, Canoui-Poitrine F, Longelin-Lombard C, Aparicio T, Ganne N, Wind P, et al. Diagnostic performance of gait speed, G8 and G8 modified indices to screen for vulnerability in older cancer patients: the prospective PF-EC cohort study. Oncotarget 2017;8(31):50393-402.

[29] Abdel-Halim M, Wu H, Poustie M, Beveridge A, Scott N, Mitchell PJ. Survival after non-resection of colorectal cancer: the argument for including non-operatives in consultant outcome reporting in the UK. Ann R Coll Surg Engl 2019;101(2):126-32.

[30] Quinn EM, Meland E, McGinn S, Anderson JH. Correction of iron-deficiency anaemia in colorectal surgery reduces perioperative transfusion rates: a before and after study. Int J Surg 2017;38:1-8.

[31] Gustafsson UO, Scott MJ, Hubner M, Nygren J, Demartines N, Francis N, et al. Guidelines for perioperative Care in Elective Colorectal Surgery: enhanced recovery after surgery (ERAS(®)) society recommendations: 2018. World J Surg 2019;43(3): 659-95.

[32] van Heinsbergen M, Maas H, Bessems S, Vogelaar J, Nijhuis P, Keijzer-Bors L, et al. Follow-up after surgical treatment in older patients with colorectal cancer: the evaluation of emerging health problems and quality of life after implementation of a standardized shared-care model. J Geriatric Oncol 2019;10(1):126-31.

[33] Thomas G, Tahir MR, Bongers BC, Kallen VL, Slooter GD, van Meeteren NL. Prehabilitation before major intra-abdominal cancer surgery: a systematic review of randomised controlled trials. Eur J Anaesthesiol (EJA) 2019;36(12):933-45.

[34] Moran J, Guinan E, McCormick P, Larkin J, Mockler D, Hussey J, et al. The ability of prehabilitation to influence postoperative outcome after intra-abdominal operation: a systematic review and meta-analysis. Surgery 2016;160(5):1189-201.

[35] Bruns ERJ, van den Heuvel B, Buskens CJ, van Duijvendijk P, Festen S, Wassenaar EB, et al. The effects of physical prehabilitation in elderly patients undergoing colorectal surgery: a systematic review. Colorectal Dis 2016;18(8) 0267-077.

[36] Looijaard SMLM, Slee-Valentijn MS, Otten RHJ, Maier AB. Physical and nutritional Prehabilitation in older patients with colorectal carcinoma: a systematic review. J Geriatr Phys Ther 2018;41(4):236-44.

[37] Carli F, Bousquet-Dion G, Awasthi R, Elsherbini N, Liberman S, Boutros M, et al. Effect of multimodal Prehabilitation vs postoperative rehabilitation on 30-day postoperative complications for frail patients undergoing resection of colorectal Cancer: a randomized clinical trial. JAMA Surg 2020;155(3):233-42.

[38] Fried TR, Bradley EH, Towle VR, Allore H. Understanding the treatment preferences of seriously ill patients. N Engl J Med 2002;346(14):1061-6.

[39] Souwer ETD, Oerlemans S, van de Poll-Franse LV, van Erning FN, van den Bos F, Schuijtemaker JS, et al. The impact of colorectal surgery on health-related quality of life in older functionally dependent patients with cancer - a longitudinal followup study. J Geriatric Oncol 2019;10(5):724-32. 